\title{
Análise de figurino como produção de moda: um estudo sobre a personagem Dumbledore e $o$ arquétipo do mago
}

Costume analysis in fashion production: a study on the character

Dumbledore and the magician archetype

\author{
Amanda Queiroz Campos \\ Universidade do Estado de Santa Catarina \\ amandaqc88@gmail.com

\section{Vilma Lago} \\ Universidade do Estado de Santa Catarina \\ vilma.lago@hotmail.com $\mathbf{x}$
}

\section{PROJËTICA}

\section{COMO CITAR ESTE ARTIGO:}

CAMPOS, Amanda Queiroz; LAGO, Vilma. Análise de figurino como produção de moda: um estudo sobre a personagem Dumbledore e o arquétipo do mago. Projética, Londrina, v. 12, n. 2, p. 292-316, 2021.

DOI: 10.5433/2236-2207.2021v12n2p292

Submissão: $13 / 05 / 2020$

Aceite: 07/12/2020 
RESUMO: No campo da moda, uma das possíveis atuações corresponde à produção cultural como figurinista. O figurino tem papel fundamental na narrativa, pois apresenta imediatamente a personagem ao público, mesmo antes de que esta se manifeste verbalmente. Este estudo apresenta uma análise de figurino da personagem Dumbledore, enfatizando as transformações da figura no decorrer dos filmes. A produção investiu no arquétipo do mago na sua construção estética do referido papel.

Palavras-chave: Design de Moda. Produção de Moda. Análise de figurino. Arquétipo.

ABSTRACT: In the field of fashion, one of the possible performances corresponds to the cultural production as a costume designer. The costume plays a fundamental role in the narrative, as it immediately introduces the character to the audience, even before they manifest themselves verbally. This study presents a costume analysis of the character Dumbledore, emphasizing the figure transformations throughout the films. The film producers invested in the magician archetype for the role's aesthetic construction.

Keywords: Fashion design. Fashion styling. Costume analysis. Archetype.

\section{INTRODUÇÃO}

O célebre crítico e teórico de teatro, Anatol Rosenfeld, defende que a ficção ocupa lugar privilegiado, onde podemos viver e apreciar diferentes papéis dramáticos. Por meio das personagens podemos experimentar seus estados de ânimo, suas condições, suas terras, o lugar e o tempo em que vivem, suas questões, dúvidas, dilemas. Parte do processo de experimentação, do tornar-se "transparente a si mesmo" e transformar-se "imaginariamente no outro", provém da relação com as 
características das personagens. A palavra personagem é introduzida ao português a partir da palavra latina persona, que, por sua vez, origina-se do etrusco phersu e do grego prósopon, com o significado de face, máscara e máscara teatral.

A máscara é também a metáfora mais adequada para explicitar o figurino na relação do ator (aquele que interpreta) e a personagem (aquilo que interpreta). Ao colocar a máscara, torna-se outro. Toma-se o lugar de uma figura dramática ao apropriar-se de símbolos que expressam visualmente, moldam e constrangem fisicamente o ator. O figuro, além de servir ao público da obra, serve aos atores como essa "segunda pele" - termo comumente associado à moda, com ênfase na função comunicativa já afirmada por Eco (1989) em Psicologia do vestir. Sendo assim, é inegável a importância das produções de figurino nos campos da dramaturgia (cinema, televisão, teatro), da dança e música, do entretenimento, etc.

As criações de figurino são realizadas por criadores, em geral, de design de moda, cuja atuação é caracterizada como a vertente cultural da produção de moda, enquanto design do vestuário e complementos. O presente estudo foi aplicado no contexto da disciplina de Produção de Moda do curso de Bacharelado em Moda da Universidade [omitido para revisão cega]. Seu objetivo foi apresentar um exemplo de análise de figurino, relacionando aspectos do figurino de uma personagem com diferentes representações desta em uma sequência de filmes. Ainda, buscou-se relacionar a caracterização da personagem escolhida (Alvo Dumbledore) por meio de suas vestes, maquiagem, cabelo e produção estética com o arquétipo do mago.

Portanto, este artigo, primeiramente [a] apresenta a profissão de produtor de moda e a atuação cultural de figurinista. Posteriormente, [b] indica-se o processo de criação de figurino e os principais aspectos que merecem a atenção dos produtores de moda durante esse projeto. Após isso, é proposto [c] um exemplo de análise de figurino, expondo, inicialmente, a trama dramática, em seguida, a personagem e, finalmente, analisando-se seu figurino em três recortes da filmografia. Por fim, os resultados associam símbolos do figurino da personagem Dumbledore com o 
arquétipo do mago/mágico, a partir da classificação de Jung. Na produção, o grande bruxo carrega traços de personalidade que são imprescindíveis para a construção da trama e que o tornam uma figura central e repleta de simbolismos. Seu figurino, portanto, consegue, com sucesso, tornar sua "aura" de importância claramente visível; transparecendo na sua aparência os ideais que cercam a figura do diretor e transmitindo, além de sabedoria e excentricidade, a liderança e a segurança que a personagem dissemina à comunidade bruxa.

\section{A ATUAÇÃO CULTURAL DA PRODUÇÃO DE MODA: FIGURINO}

Produção de moda pode ser descrita como composição de elementos que definem um estilo. Para Feghali (2004), o profissional responsável por compor uma imagem de moda, associando peças de vestuário, acessórios, cabelo, maquiagem e atitude é o produtor de moda. Andrade e Joffily (2013) apresentam o produtor de moda e suas possibilidades de trabalho, dividindo sua atuação em três áreas. A atuação [1] comercial presta-se ao serviço de marcas e revistas, na qual o profissional deve compor looks e definir conceitos a serem expressos nesses looks, mas, também, no próprio perfil dos modelos e na escolha de locações - criando imagens que despertem desejo. Já a atuação [2] institucional ou pessoal, exige que o produtor de moda atue como consultor de estilo e imagem e personal stylist, criando uma imagem pessoal ou corporativa. Por fim, a [3] cultural envolve o desempenho de figurinos de filmes, séries, novelas, shows, etc.

Como apresentado na introdução do presente artigo, a primeira ideia de figurino foram as máscaras de teatro grego. As máscaras tinham força não apenas na apresentação das personagens ao público, desempenhando função simbólica na construção do traje, mas, principalmente, a partir de seu poder ritualístico, como elementos de transformação dos atores e atrizes na caracterização de diferentes personagens. De acordo com Scholl, Vecchio e Wendt (2009, p. 4), um figurino é capaz de imprimir, além do conteúdo manifesto, "aspectos latentes da 
personalidade da pessoa, inferidos de acordo com sua apresentação. Estes signos é que são responsáveis pelo adequado delineamento do perfil psicológico da personagem - se esta é arrogante, simplória, narcísica, agressiva, etc."

Cunningham (2019, p. 1) defende que as vestes de um intérprete potencializam "o poder da imaginação, expressão, emoção e movimento dentro da criação e projeção do caráter do espetáculo". Ao mesmo tempo, as vestes de figurino dão visibilidade a todo um sistema de relações e práticas sociais das personagens: suas ocupações, gênero, personalidade, etc. Assim, o figurino tem um papel central na produção completa, pois pode definir a aceitação ou rejeição de uma personagem pelo público. Na história da dramaturgia brasileira, onde a telenovela desfruta de condição privilegiada no interesse dos espectadores, itens dos figurinos de personagens foram amplamente adotados como expressão da popularidade e atratividade destes. Como afirma Saadi (2006) em obra sobre a Cia dos Atores, "antes mesmo de falar o personagem, falam seu corpo e sua roupa".

É, portanto, inegável a importância da atuação de figurinista para a produção da peça, preparo das personagens e interação com o público espectador. Como afirma Nacif (2012, p. 295),

[...] O figurino, além de representar a personagem, representa a natureza da obra literária. Podem-se transpor para a linguagem visual as referências estilísticas contidas no texto. Cada gênero guarda uma coerência interna entre a representação das personagens e sua caracterização pelo figurino em termos de formas, cores, texturas: num drama ou numa comédia, o traje de um rei tem uma forma e um valor simbólico, diferentes. O manejo adequado dos elementos da linguagem visual contribui para que o figurino constitua uma para - narrativa que se revela de imediato aos olhos do espectador, intensificando os valores expressos no discurso dramático, prenunciando o que está por vir. 
Sendo assim, ao executar um projeto de figurino, o produtor precisa levar em consideração todos os aspectos da personagem. Os principais aspectos e etapas desse projeto serão explicitados no próximo item.

\section{O PROJETO DE FIGURINO}

O figurinista consagrou sua credibilidade ao conferir realismo e encantamento às personagens. O trabalho exige "valer-se de formas, estilos e cores, exteriorizando a personalidade das figuras, [...] a ponto de fazer parecer que ele foi capaz de escolher as próprias roupas e a maneira de usá-las, como um reflexo de seu caráter" (ROCHA, 2014). O figurino não é composto apenas por peças de roupas, mas congrega cabelo, maquiagem, acessórios e adereços (ARRUDA; BALTAR, 2008). Todos eles devem ser bem orquestrados de forma a construírem a trama narrativa por meio das personagens e suas aparências, em conformidade com o universo espacial, temporal e onírico a ser representado.

Os figurinos podem expressar os tempos históricos, as diferentes culturas e localidades, os contextos sociopolíticos e econômicos, visões de mundo e estilos de vida. Levar em conta a época em que se passa a trama é particularmente importante no caso de produções de época. Nas produções contemporâneas, a ênfase recai mais sobre o perfil psicológico e a posição da personagem na trama, buscando expressar seu status, profissão, idade e seu modo de pensar. As personagens são descritas por roteiristas e diretores com o máximo de características humanas, de forma que o ator possa interagir com o público por meio da personagem, e o figurinista contribui para esta interação [comunicação].

A figurinista Rebecca Cunningham (2019) apresenta, na obra recém reeditada - The Magic Garment: Principles of Costume Design, o processo padrão de desenvolvimento de um figurino. A primeira etapa consiste em [1] ler e estudar o roteiro. O roteiro já indica de forma direta ou indireta as informações sobre períodos históricos; personagens; mudanças, ações e disfarces; clima e estilo geral. 
Após a leitura, deve-se partir para [2] a colaboração entre o figurinista e o diretor. Para Cunningham (2019, p. 10), a conversa sobre ideias, efeitos, imagens, conceitos, cronogramas e outras informações auxilia que a equipe caminhe na direção de um objetivo comum. Além do diretor, é imprescindível levar em consideração outros participantes da equipe técnica: o diretor de cenografia, o diretor de iluminação, diretor de coreografia - se aplicável - dentre outros. Nesses e em outros casos, decisões em uma dessas áreas interferem nas demais e na produção em geral.

Tendo compreensão suficiente, conduz-se à [3] pesquisa. A pesquisa pode ser histórica, especificando o período em que se passa a trama, pois dele decorrerá o tipo de pesquisa necessário. Enquanto narrativas contemporâneas podem envolver viagens de estudos, narrativas de época podem incluir pesquisas de obras de arte, literatura, museus e relíquias. Uma primeira etapa de pesquisa serve mais para inspiração do figurinista, sendo mais abstrata, do que uma mais objetiva para determinar materiais, técnicas, modelagens e modelos. Os resultados da pesquisa preliminar normalmente são expressos em um painel visual ainda sem desenhos de vestuário, mas com colagens de cores, formas, texturas e um ambiente mais geral.

O [4] desenvolvimento dos figurinos é a etapa mais detalhada. Ela é conduzida produzindo-se rascunhos de looks para manifestar a abordagem pretendida pelo figurinista para cada personagem. Esses primeiros esboços servirão ao propósito de se conduzir uma nova discussão com o diretor, assegurando-se agora visualmente - que os figurinos para cada personagem serão desenvolvidos dentro de uma expectativa coincidente entre as partes. Quando a linha geral é aprovada, a equipe de figurino deve seguir a geração de ideias e conferir se os figurinos de uma mesma e das diferentes personagens, o cenário e a iluminação estão "unificados" (ibid., p. 12). Segue-se para a finalização dos desenhos e a escolha dos tecidos, materiais e técnicas de modelagem e execução.

Por fim, também é responsabilidade do figurinista [5] orquestrar a realização do figurino, assegurando-se do seu melhor desempenho na peça. Para tal, ele e sua equipe devem acompanhar os ensaios, as sessões de fotos, a pré-estreia e os 
lançamentos. De maior importância é orientar as camareiras e passadeiras sobre os cuidados com as peças, como devem ser guardadas, manipuladas e vestidas. Também, é relevante indicar possíveis ajustes a serem feitos durante a temporada e eventuais reparos de desgastes que podem ocorrer no período de filmagem ou enquanto a peça estiver em cartaz. Como afirma Cunningham, o figurino é um traje mágico. Cabe ao figurinista garantir que, durante o espetáculo, nada perturbe a aura fantástica da narrativa teatral, cumprindo a tarefa de, por um período circunscrito de tempo, levar atores e espectadores a outras terras, outros tempos, outras realidades.

\section{ANÁLISE DE FIGURINO: UM EXEMPLO DE DUMBLEDORE EM HARRY POTTER}

Assim, propôs-se, no contexto da disciplina Produção de Moda do curso de Bacharelado em Moda da Universidade [omitida para revisão cega], proceder a uma análise de figurino à escolha dos discentes. A análise deveria considerar o [1] objetivo da produção, o [2] contexto dramaturgo, apresentar a [3] personagem e, por fim, proceder à atividade analítica ao indicar a [4] adequação do figurino em questão. Ou seja, indicar se a proposta do figurinista corresponde [1] às exigências e limitações de encenação ou filmagem; [2] à trama narrativa, seu tempo histórico, localização geográfica e aspectos culturais referentes a ela, à estação do ano e/ou outras definições do roteiro e; por fim, [3] à personalidade da personagem. A etapa de conferência da adequação é primordial para o exercício reflexivo do produtor de moda, que em qualquer atuação deve escolher o visual mais adequado à produção.

\section{O filme Harry Potter}

O universo mágico de Harry Potter surgiu nas últimas décadas como uma onda de influência para o mundo das histórias de ficção. A trama do pequeno bruxo, que numa reviravolta descobre verdades surpreendentes sobre seu passado e constrói uma nova história com o mundo da magia, influenciou uma geração inteira. Independente do contexto, a série de romances mantém seu espaço como 
uma saga atemporal, divertida e cheia de lições sobre amor, amizade e união. Para a redação dos livros - os quais foram rapidamente adaptados para o cinema - a escritora J. K. Rowling construiu, em detalhes, um universo mágico que combina a imaginação da própria idealizadora com arquétipos do mundo da bruxaria. As construções psíquicas compartilhadas pela coletividade são facilmente percebidas ao longo da história e fazem com que a trama seja enriquecida e encante diversos públicos.

A saga conta a história de Harry Potter, um garoto magricela e que carrega uma estranha cicatriz em forma de raio na testa. Harry vive em companhia de seus tios, Válter e Petúnia Dursley, e de seu primo mimado Dudley Dursley (Duda) - na Rua dos Alfeneiros, $n^{\circ} 4$, Little Whinghing, Surrey -, uma família completamente monótona e comum e que o enxerga como estranho e indesejável, reprimindo-o sempre que possível. Após viver quase 11 infelizes e tediosos anos com os Dursley, o garoto descobre, repentinamente, que é um bruxo, e se depara com a oportunidade de frequentar Hogwarts, uma excepcional escola de magia e bruxaria reservada a todos aqueles dotados de "talentos mágicos", independente de serem provindos de famílias bruxas ou não. O diretor dessa escola é o excêntrico Alvo Dumbledore, um dos bruxos mais sábios e poderosos de seu tempo.

Ao embarcar nessa aventura, o jovem bruxo vai, aos poucos, entrando em contato com um universo mágico repleto de segredos e desvendando mistérios sobre seu passado, o qual esconde a verdadeira história sobre seus pais e sua ligação com Voldemort, bruxo das trevas e vilão da saga. Harry descobre que seu nome é amplamente conhecido pela comunidade bruxa, carregando histórias das quais o próprio garoto nem fazia ideia. Para que sua segurança e daqueles que o rodeiam seja mantida, Harry precisa entrar nessa luta contra o Lorde das Trevas. Porém, o pequeno bruxo não está sozinho; a amizade e a cooperação se revelam importantes aliados para enfrentar os desafios. Juntos, Harry Potter, seus amigos e a comunidade de Hogwarts cooperam para que a paz seja novamente restaurada ao mundo bruxo. 
A descoberta de que Harry é um bruxo introduz o garoto a um universo fantástico e repleto de surpresas, as quais contrastam de maneira perceptível com as "normalidades" da vida sem magia que conduzia junto aos Dursley, nos subúrbios da Inglaterra. O mundo mágico de fantasias e ocultismo se faz presente nas representações do cotidiano e nas ambientações do mundo mágico, tanto expressas em texto (no livro) como em imagens (no filme). Tais representações revelam, em diferentes detalhes, as significações de magia e encantamento que perpassam a história.

Nessa mesma perspectiva, a criação de personagens que se enquadrem nas especificações de cada contexto traz elementos combinados que formam o conjunto completo da significação, sendo o figurino uma parte importante deste. Os figurinos dos personagens que pertencem ao mundo mágico da trama expressam essas qualidades arquetípicas de formas evidentes, pois são exploradas - muitas vezes, até de modo cômico - as preferências das personagens mágicas por vestimentas "chamativas e escandalosas". Essa forma incomum e esquisita de se vestirem pode ser associado ao passado, à tradição, ao antiquado. O figurino, portanto, expressa a inadequação aos modos de vestir da comunidade não mágica (a qual, na trama, é denominada trouxa), que por parte dos bruxos é vista como estranha, deslocando o lugar de estranhamento.

\section{A personagem}

Como bom exemplo da peculiaridade do mundo mágico, a personagem escolhida para análise de figurino é um dos maiores bruxos de todos os tempos, Dumbledore, que traz à ambientação do filme uma representação bem aprofundada dos costumes da comunidade mágica. Alvo Percival Wulfric Brian Dumbledore (18811997) é uma figura ímpar na trama de Harry Potter. Nascido em uma família mestiça (metade bruxa e metade trouxa), a personagem passou por momentos delicados e traumáticos durante sua infância e juventude. Essas experiências em tenra idade levaram-no a construir uma personalidade forte, madura e sábia ao longo dos anos, aprendendo com seus erros e tornando-se uma figura inspiradora e com grande significância dentro da comunidade bruxa. 
Projética, Londrina, v. 12, n. 2, p. 292-316, agosto 2021

As funções de um produto refletem em seus significados, tendo como foco conceitos de emoção, afeto, sentimento e amor. O objeto passa a ser um portador de representações, estabelecendo com o usuário relações em nível subjetivo, emocional e cognitivo. (NIEMEYER, 2008, p. 56).

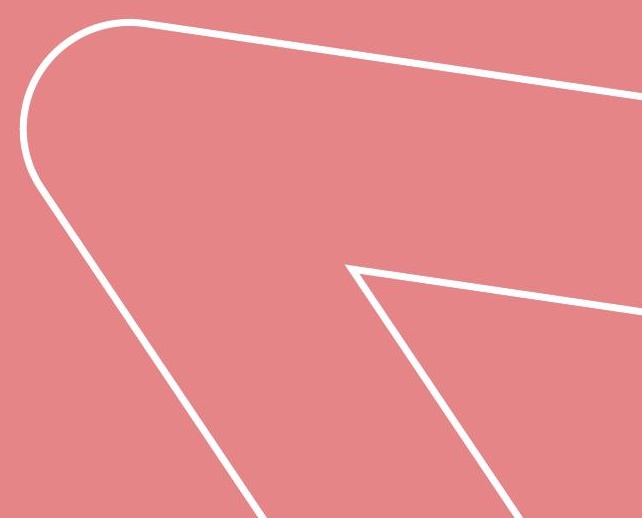


Graças a tantos feitos heroicos e servis à essa comunidade, além do amplo conhecimento, o mago ganhou o prêmio da Ordem de Merlin Primeira Classe, e desempenhou os cargos de Presidente da Suprema Corte de Feiticeiros e Diretor da Escola de Magia e Bruxaria de Hogwarts, uma das várias escolhas existentes no mundo bruxo. Sua bravura e sabedoria Ihe renderam um legado importante, sendo considerado, por muitos, uma lenda, e invejado ou temido por tantos outros; inclusive pelo vilão da saga, Voldemort. Por esses motivos, Dumbledore se tornou uma das figuras mais importantes da comunidade bruxa no século XX, mais precisamente na última década ${ }^{1}$ - apesar de grande parte da audiência ignorar o período histórico da série, creditando-a uma "aura" atemporal que a encaixaria a qualquer período histórico.

Todas essas características são importantes para compor a apresentação visual da personagem, pois transformaram a personalidade de um dos maiores e mais sábios bruxos de todos os tempos. Logo, esses aspectos também foram sutilmente transmitidos pelo figurino. Mesmo dentro da comunidade bruxa, Dumbledore possui uma aparência particular e perceptível, que se destaca dos demais mágicos. Essa figura apresenta forma muito semelhante ao arquétipo do mago - o qual será detalhado mais a frente neste trabalho - correspondendo à figura mágica exemplar dentro das histórias de bruxaria, auxiliando para situar leitores e espectadores na trama a partir de repertório simbólico identificado em outras representações desta mesma temática bruxólica.

[1] Um olhar atento percebe alguns poucos easter eggs - segredos de caráter humorístico escondido em qualquer tipo de sistema virtual, incluindo músicas, filmes, websites, jogos eletrônicos, etc. - como os objetos do mundo trouxa, que a situam no tempo contemporâneo. 


\title{
O figurino de Alvo Dumbledore em Harry Potter e a Pedra Filosofal
}

O primeiro livro narra o primeiro ano escolar do protagonista Harry Potter em Hogwarts e também o primeiro contato, tanto dessa personagem quanto do público, com o mundo fantástico de bruxaria da franquia. Um dos artifícios utilizados para representar claramente a atmosfera mágica foi o figurino de Dumbledore. O figurino utilizado no filme segue de maneira similar ao detalhamento descrito no livro:

\begin{abstract}
Ninguém jamais vislumbrara nada parecido com este homem na rua dos Alfeneiros. Era alto, magro e muito velho, a julgar pelo prateado dos seus cabelos e de sua barba, suficientemente longos para prender no cinto. Usava vestes longas, uma capa púrpura que arrastava pelo chão e botas com saltos altos e fivelas. Seus olhos azuis eram claros, luminosos e cintilantes por trás dos óculos em meia-lua e o nariz muito comprido e torto, como se o tivesse quebrado pelo menos duas vezes. O nome dele era Alvo Dumbledore (ROWLING, 2000a, p.13).
\end{abstract}

Dumbledore utiliza durante o primeiro filme um figurino extremamente adornado e rico em ornamentos, composto por: (a) um sobretudo de modelagem reta e sem muitos recortes em tecido encorpado e opulente, (b) uma túnica de veludo violeta ampla e com mangas compridas, com ricos detalhes em dourado e bordados, (c) um chapéu pontudo feito dos mesmos materiais da túnica, (d) um óculos de meia-lua dourado (que é marca registrada do diretor), e (e) barba e cabelos longos e brancos. As cores predominantes do seu figurino são violeta, dourado e detalhes em preto. Essa paleta colorística é extremamente consoante com a descrição da personagem Alvo Dumbledore. 
Figura 1 - Alvo Dumbledore.

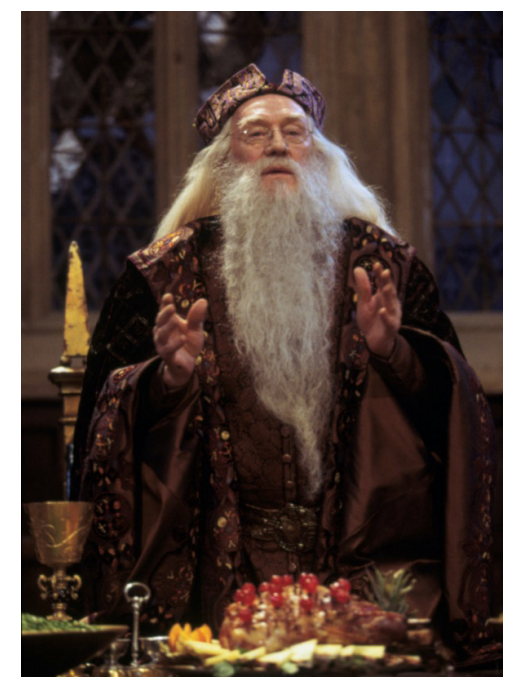

Fonte: Wizarding World Digital (2017). ${ }^{2}$
Figura 2 - Dumbledore e Minerva.

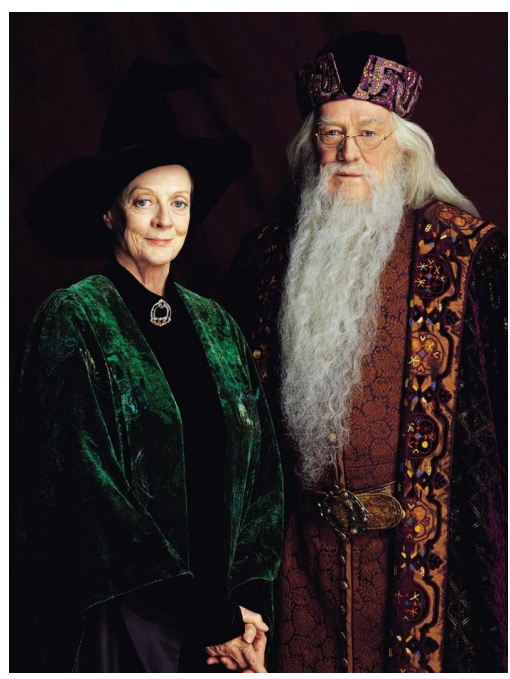

Fonte: Harry Potter Fan Zone (2003b). ${ }^{3}$

A cor violeta é fortemente associada à magia e ao mistério, reforçando a ideia de uma cor tradicional e tipicamente utilizada por bruxos. É certamente a cor que a autora J.K. Rowling utilizaria para vestir Dumbledore, pois reforça sua sabedoria e conhecimentos, além de sua magia e poderes avançados e sua estrita ligação com o mundo bruxo, uma vez que a cor também é associada à alquimia. A alquimia é a ciência que buscava a pedra filosofal; uma rocha capaz de transformar qualquer objeto em ouro, além de produzir o elixir da longa vida, tornando qualquer um que a possuísse imortal. A série de livros e filmes associa alquimia à feitiçaria e essa ligação não se dá por acaso. A primeira obra do conjunto trata justamente do almejado objeto precioso, a pedra filosofal, e a personagem Alvo Dumbledore possui relações muito próximas com o alquimista em posse da pedra, Nicolau Flamel.

[2] Disponível em: https://www.wizardingworld.com/features/important-pieces-ofdialogue-from-philosophers-stone. Acesso em: 12 de Maio de 2020.

[3] Disponível em: https://www.harrypotterfanzone.com/pictures/professor-mcgonagallprofessor-dumbledore-philosophers-stone-portrait/. Acesso em 12 de Maio de 2020. 
A referida cor violeta contrasta com o dourado predominante dos detalhes. A "cor" dourado é diretamente associada ao luxo e à riqueza, já que expressa o elemento ouro - fazendo novamente ligação com a alquimia. Além disso, ambas as cores em conjunto, violeta e dourado, revelam magia, sabedoria, elevação - tanto espiritual quanto de conhecimento -, nobreza e mistério. Os tecidos utilizados no traje são encorpados, pesados, robustos, ricos em texturas e adornos e transparecem a noção de riqueza. Isso, pois são tecidos caros e com tingimentos relacionados ao alto custo; à nobreza, portanto. Ao mesmo tempo, a modelagem dos trajes é ampla, com linhas retas e pouco volume, apresentando bom caimento. Esse último ponto expressa que, apesar de nobre e notável, a personagem possui certa modéstia e moderação. É um traje escolhido para destacar o diretor dos demais indivíduos presentes na escola; não como um rei ostentador exibicionista, mas como uma figura dotada de nobreza e sapiência.

\section{O figurino de Dumbledore em Harry Potter e a Câmara Secreta}

Assim como o primeiro, o figurino de Dumbledore no segundo filme expressa, evidentemente, relação com a magia. Ele constitui-se de (a) uma túnica ampla que lhe cobre todo o corpo, (b) um chapéu pontudo, (c) óculos em meia-lua, além da (d) barba e cabelos brancos e destacadamente compridos. Nesta ocasião, as cores predominantes são vermelho intenso em tonalidade escarlate e, novamente, o dourado. Essa combinação de cores também está associada à magia, porém, o vermelho pode estar associado à casa Grifinória - casa de Hogwarts a qual pertenceu o diretor, que valoriza a coragem e a bravura, presentes na combinação com o dourado. As formas, tecidos, texturas e cores desse figurino são muito similares às do primeiro; também projetado para conferir destaque à figura do diretor, associando-o com as tradições do mundo bruxo, extremamente ligadas aos costumes do passado. 
Figura 3 - Alvo Dumbledore (Harry Potter e a Câmara Secreta).

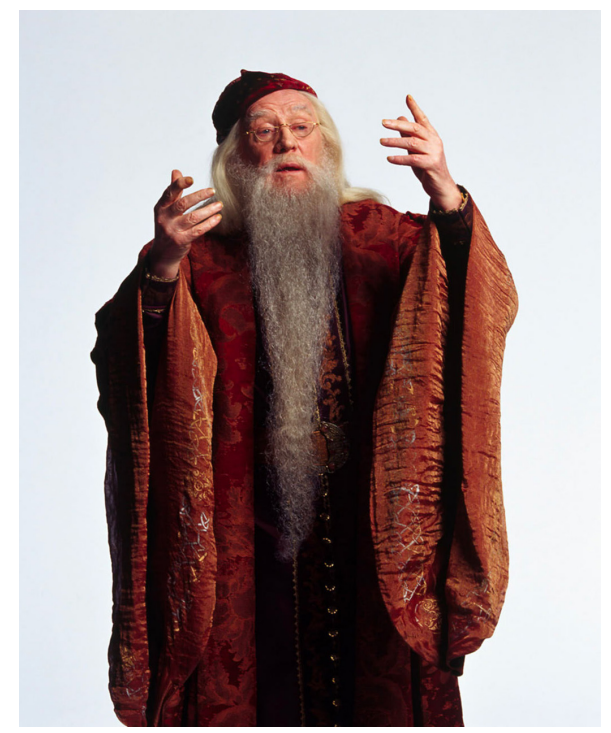

Fonte: Harry Potter Fan Zone (2003a). ${ }^{4}$

Como já indicado em relação às cores vermelha e dourado, o traje parece fazer referência à casa Grifinória, que possui destaque no filme por ser a casa à qual pertence o protagonista da trama, Harry Potter. Em relação à casa, trata-se parcialmente sobre a espada de Godric Gryffindor, um dos fundadores de Hogwarts, e o simbolismo de honra de pertencimento a essa que é a casa da valentia. Além disso, o figurino de Dumbledore dialoga com as cores de Fawkes, a fênix do diretor (predominantemente vermelha), pássaro que simboliza o renascimento, a força e a resistência, e que possui papel fundamental na história. A cor vermelha, também, contrasta fortemente com outra cor em destaque no filme, a cor verde - formando um par complementar e oposto. Verde é a cor da Casa Sonserina, que é colocada em referência por ser a casa de Tom Riddle, o Voldemort, que é o antagonista na série. Logo, é explícita a oposição entre as casas e as personagens.

[4] Disponível em: https://www.harrypotterfanzone.com/pictures/albus-dumbledorechamber-of-secrets-portrait/. Acesso em: 12 Maio 2020. 


\section{O figurino de Dumbledore no restante da Saga}

A partir do filme Harry Potter e o Prisioneiro de Azkaban o figurino de Dumbledore se torna praticamente inalterado e, da mesma forma, parece acompanhar o desenvolvimento da história. Isso pois, aos poucos, a trama perde o "ar" de magia, graça e perigos ingênuos e facilmente resolvíveis e torna-se uma história mais sombria, complexa e perigosa. Voldemort ganha poder e Dumbledore mantém-se como figura imprescindível para a manutenção da ordem e segurança. Seu figurino reflete tais mudanças; portanto, torna-se mais sóbrio, sério e seguro.

Figuras 5 e 6 - Alvo Dumbledore em Harry Potter e o Prisioneiro de Azkaban).

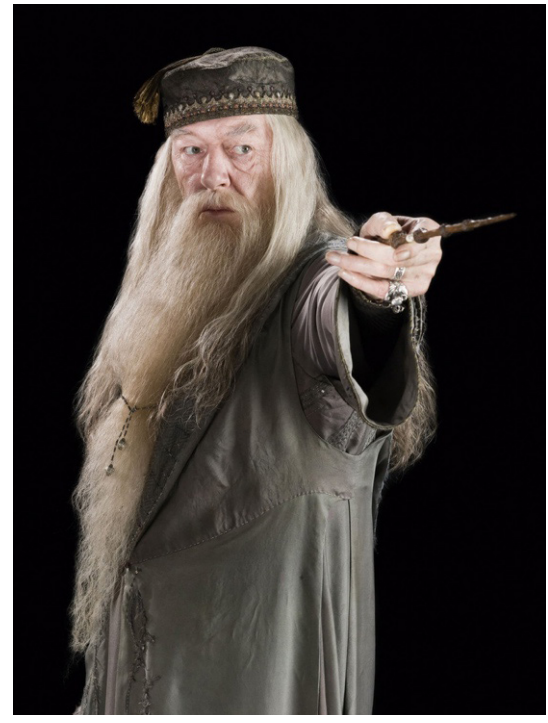

Fonte: Harry Potter Fan Zone (2003a). ${ }^{5}$

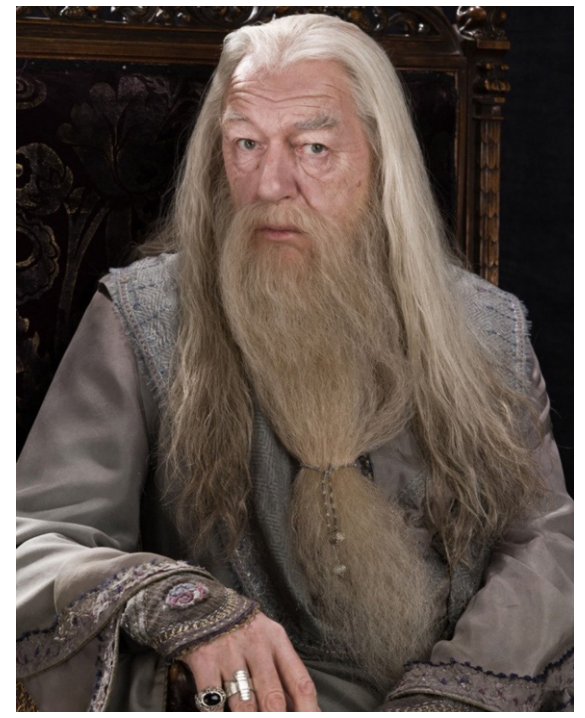

Fonte: Wizarding World Digital (2018). ${ }^{6}$

[5] Disponível em: https://www.harrypotterfanzone.com/pictures/albus-dumbledorehalf-blood-prince-portrait/. Acesso em: 12 Maio 2020.

[6] Disponível em: https://www.wizardingworld.com/features/things-you-may-not-havenoticed-about-albus-dumbledore. Acesso em: 12 Maio 2020. 
A partir do terceiro filme, ocorreu a troca do ator que interpreta o bruxo diretor de Hogwarts, Alvo Dumbledore, ocorrida devido à morte do ator Richard Harris (que interpretou o diretor nos dois primeiros filmes) em 2002, passando o papel para Michael Gambon. Houve, também, a partir do filme Harry Potter e o Prisioneiro de Azkaban, a troca de figurinista para Jany Temime, que trabalhou na saga até o último filme de Harry Potter, Relíquias da Morte parte 2. Temime criou maior unidade do figurino durante os anos em que esteve à frente do Costume and Wardrobe Department, tornando-o mais uniforme ao longo dos filmes. Igualmente, o diretor de Hogwarts, Dumbledore, consolidou-se visualmente de forma marcante no restante da trama - e, portanto, a análise do figurino sintetizou os últimos seis filmes. ${ }^{7}$

As vestes do figurino de Dumbledore perdem a enorme quantidade de bordados e adereços dourados e chamativos e ganham delicados bordados em violeta, azul e prata. Além disso, o bruxo passa a usar acessórios como anéis grandes e marcantes e um pequeno prendedor em sua barba, tornando-a mais reta e fina, o que alonga a sua fase e a sua silhueta. Do mesmo modo, os tecidos pesados de veludo são substituídos por tecidos mais leves, com mais fluidez e mais suscetíveis a expressarem a movimentação do corpo. Dessa forma, a escolha de tecidos fluidos confere ao andar rápido do diretor um ar de importância, elevação e dinamismo.

[7] Harry Potter e o Prisioneiro de Azkaban (2004), Harry Potter e o Cálice de Fogo (2005), Harry Potter e a Ordem da Fênix (2007), Harry Potter e o Enigma do Príncipe (2009), Harry Potter e as Relíquias da Morte: Parte 1 (2010), Harry Potter e as Relíquias da Morte: Parte 2 (2011). 
As cores desse figurino variam entre os seis filmes, mas são marcadas predominantemente por lilás claro e azul em tons pastéis. Como já dito anteriormente, o violeta está associado à magia e ao mistério. Porém, as cores mais claras e apagadas - o violeta, agora apagado em tom lilás, e o azul também ameno acompanham a passagem para uma atmosfera na qual Voldemort instala o medo, e Dumbledore se torna uma figura de apoio, seriedade e serenidade dentro da trama, conformando a figura de um verdadeiro sábio. Há também a incidência considerável do cinza. Não coincidentemente, essa é a cor que encobre o figurino de Dumbledore pouco antes de sua morte, em O Enigma do Príncipe. Também no último filme, Harry Potter e as Relíquias da Morte: Parte 2, o diretor de Hogwarts aparece na mente de Harry trajando cinza e marca um clima mais sombrio, perigoso e triste na história em que ele é apenas memória.

Em termos de peças do vestuário, Dumbledore frequentemente veste uma túnica inteira, que lhe cobre todo o corpo. Essa túnica é de tecido liso e sem brilho (semelhante ao linho ou outro tecido natural fosco), com um detalhe de peitilho, ou seja, a região do torso superior, peitoral, é feita de um tecido especial que se destaca do tecido da túnica, desenhando uma forma V. Este tecido especial tem uma estampa corrida, provavelmente um brocado rico, mas não exageradamente suntuoso. Também sobre a túnica, às vezes, nota-se uma corrente prateada e longa, que se sobrepõe ao peitoral médio da personagem.

Até o quinto filme, Harry Potter e a Ordem da Fênix, Dumbledore também veste um chapéu em formato redondo e pequeno, seus óculos de meia-lua e sapatos mocassins. A retirada do chapéu e a simplificação do traje a partir de O Enigma do Príncipe, filme no qual a personagem morre, parece torná-lo mais "humano", próximo da realidade. As simplificações da vestimenta aproximam a personagem dos demais à sua volta, ainda que mantenha um comedido destaque enquanto douto. Por meio do vestuário, torna-se expressivo que esse grande e sábio bruxo é, do mesmo modo, um homem que, assim como os outros, também sofre, sente medo e erra. Acima de tudo, as vestes simplificadas e cinzas anunciam a proximidade do seu fim. 


\section{O figurino de Dumbledore e o arquétipo do mago}

O termo "arquétipo" tem suas origens na Grécia Antiga, com as raízes arché (princípio) e tipos (marca ou tipo). O conceito representa o primeiro de algo, um modelo, um protótipo. A partir do arquétipo, outras ideias, figuras e conceitos são copiados, remodelados e emulados. Apesar de ser aplicado desde Platão, o termo é mais conhecido contemporaneamente graças à psicologia analítica de Jung. Resumido de forma rudimentar, arquétipos são imagens primordiais que dão sentido às narrativas passadas de geração em geração, formando o inconsciente coletivo, servindo como estruturas para a modelagem de fenômenos psíquicos, desenvolvimento da psique também da expressão. Também associados às questões universalmente humanas, como vida e morte, os arquétipos representam "moldes" fundamentais da experiência e afetam nossas emoções de forma intensa e intuitiva.

Jung (2000) identificou alguns arquétipos, como o herói, a criança, a mão, o velho sábio, etc. Os arquétipos foram popularizados em modelos chamados neoarquetípicos, cujas definições foram sistematizadas por Faber e Mayer (2008). Nessa sistematização, o velho sábio corresponde ao mágico. “Represented by the physicist; the visionary; the alchemist. Seeking the principles of development and how things work; a teacher, a performer or a scientist. Fundamentalist interested in natural forces, transformations, and metamorphoses" (FABER; MAYER, 2008, p. 3). O arquétipo do mágico é amplamente notável na literatura, na música e no cinema, sendo percebido de forma mais sutil ou indireta ou, ainda, explicitamente, como é o caso da série Harry Potter.

No universo de Harry Potter, a presença de arquétipos é constante e auxilia a situar o interlocutor dentro do universo da magia. Nesse contexto, Dumbledore é uma figura marcante como expressão do arquétipo do mágico. A personagem é um mestre em feitiçaria, magia e sabedoria. O modelo do mago está intimamente ligado às ideias medievais de magia, principalmente relacionadas com a alquimia e 
a busca pela pedra filosofal; mas, acima disso, o mago seria uma pessoa elevada, que possui consciência de si e dos outros, que é sábio, humilde e um líder natural. Sua figura ancora.

Em termos de representação, é uma personagem frequentemente apresentada como idosa; a idade mais elevada, portanto, expressa maior maturidade e sabedoria provindas das experiências vividas. Logo, os cabelos são brancos e longos e, no caso das personagens masculinas, há também longas barbas. O olhar é, ao mesmo tempo, imponente e bondoso, espera pacientemente àqueles que vem ao seu encontro. As vestes são comumente amplas e longas, cobrindo o corpo. A silhueta quase amorfa parece negar a "carne", a humanidade dessas figuras, nas quais o intelecto e uma certa divindade sobressaem. Também, é comum que magos façam uso de um chapéu pontudo, novamente associando à verticalidade e elevação, e dando ênfase à cabeça e à mente dessas figuras. Magos e bruxos carregam varinhas, cajados, e outros possíveis objetos de poder, como um talismã; no caso de Dumbledore, colares, anéis e a presilha que acolcheta a longa barba.

\section{CONCLUSÃO}

Um figurino é uma forma de comunicar diferentes aspectos sobre uma narrativa, ficcional ou não, e sobre suas personagens. Por envolver principalmente as vestes das personagens, o trabalho de figurinista exige a formação, ou, ao menos, habilidades comuns às da área de Moda. Nela, a atuação de figurinista recai sobre o eixo cultural da produção de moda, cujo objetivo é construir uma mensagem por meio de um visual, de forma a projetá-lo com o máximo de coerência com a trama e, também, gerar encantamento e despertar o interesse do público. 
Análise de figurino como produção de moda... mago CAMPOS, A. Q.; LAGO, V.

Na área de moda, a atuação de figurinista recai sobre o eixo cultural da produção de moda, cujo objetivo é construir uma mensagem por meio de um visual.

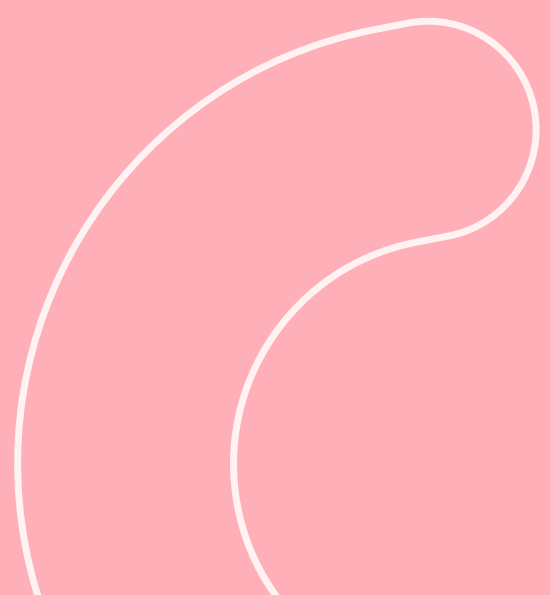


De forma a conduzir uma reflexão sobre o planejamento de figurino, este artigo propôs-se a analisar os figurinos de uma mesma personagem em diferentes filmes de uma mesma franquia. Assim, buscou-se analisar aspectos coincidentes e dissidentes, ponderando as mudanças operadas no decorrer da trama. Considerase, por conseguinte, que os figurinos de Alvo Dumbledore nos filmes Harry Potter foram bem explorados e se acomodam ao universo da magia. Eles atingem ao objetivo de colocar o diretor de Hogwarts como uma figura central dentro da história, acompanhando o desenrolar da trama, refletindo adequadamente os principais acontecimentos e corroborando com a narrativa da autora, J. K. Rowling.

Para tal, fica evidente o investimento no arquétipo do mago/mágico, o qual é amplamente utilizado para a representação de figuras mágicas, sendo representado em diversas histórias de ficção além de Harry Potter, como em 0 Senhor dos Anéis, A Caverna do Dragão e outros. Dumbledore claramente explora tal modelo, sendo que seus trajes representam a tradição bruxa, com túnicas e capas, com ressonância à Era Medieval, que escondem o corpo e dão destaque à cabeça (mente). A isso, assinala-se o uso de cores associadas ao misticismo e à soberania, ambas ligadas à querida e imponente figura do mago diretor. As vestes e a aparência de Dumbledore o deslocam temporalmente do presente, opondo a personagem e toda a comunidade mágica ao comum "mundo trouxa", e tornando-o a representação ideal de um homem com imenso conhecimento e poder. 
Análise de figurino como produção de moda... mago CAMPOS, A. Q.; LAGO, V.

\section{REFERÊNCIAS}

1. ANDRADE, Maria; JOFFILY, Ruth. Produção de moda. São Paulo: Editoria Senac, 2013.

2. ARRUDA, Lílian; BALTAR, Mariana. Entre tramas, rendas e fuxicos: o figurino na teledramaturgia da TV Globo. Rio de Janeiro: Editora Globo, 2008.

3. CUNNINGHAM, Rebecca. The magic garment: principles of costume design. 3rd ed. Illinois: Waveland Press, 2019.

4. ECO, Umberto. O hábito fala pelo monge. In: ECO, Umberto. Psicologia do vestir. Lisboa: Assirio e Alvim, 1989. p. 3-20.

5. FABER, Michael A.; MAYER, John D. Resonance to archetypes in media: there's some accounting for taste. Journal of Research in Personality, New York, v. 43, n. 3, p. 307-322, June 2009. Disponível em: https://www.sciencedirect. com/science/article/abs/pii/S0092656608001566. Acesso em: 31 out. 2020.

6. FEGHALI, Marta Kasznar. As engrenagens da moda. Rio de Janeiro: Senac, 2004.

7. HARRY POTTER FAN ZONE. Portrait of Albus Dumbledore. 2003a. Disponível em: https://www.harrypotterfanzone.com/pictures/albus-dumbledorechamber-of-secrets-portrait/. Acesso em: 12 maio 2020.

8. HARRY POTTER FAN ZONE. Portrait of Professor McGonagall and Professor Dumbledore. 2003b. Disponível em: https://www.harrypotterfanzone.com/ pictures/professor-mcgonagall-professor-dumbledore-philosophers-stoneportrait/. Acesso em: 12 Maio 2020. 
Projética, Londrina, v. 12, n. 2, p. 292-316, agosto 2021

9. JUNG, Carl Gustav. Os arquétipos e o inconsciente coletivo. Petrópolis: Vozes, 2000.

10. ROCHA, Katiucha Barcelos Carneiro Montenegro da. Desenvolvimento de produto: figurino do game Hedone. Fortaleza: Universidade Federal do Ceará, 2014. Artigo Monográfico.

11. NACIF, Maria Cristina Volpi. O figurino e a questão da representação da personagem. In: VIANA, Fausto; MUNIZ, Rosane. (org.). Diário de pesquisadores: traje de cena. São Paulo: Editora Estação das Letras e Cores, 2012, v. 1, p. 291-295.

12. ROWLING, Joanne Kathleen. Harry Potter e a pedra fillosofal. Rio de Janeiro: Rocco, 2000a.

13. SAADI, Fátima. Na companhia dos atores - ensaios sobre os 18 anos da cia dos atores Enrique Diaz. Rio de Janeiro: SENAC RJ, 2006.

14. SCHOLL, Raphael Castanheira et al. Figurino e moda: intersecções entre criação e comunicação. In: CONGRESSO DE CIÊNCIAS DA COMUNICAÇÃO NA REGIÃO SUL, 10., 2009, Blumenau. Anais [...]. Blumenau: INTERCOM, 2009. Disponível em: http://www.intercom.org.br/papers/regionais/sul2009/ resumos/R16-0855-1.pdf. Acesso em: 20 abr. 2020.

15. WIZARDING WORD DIGITAL. Partes importantes do diálogo da pedra filosofal. 2017. Disponível em: https://www.wizardingworld.com/features/ important-pieces-of-dialogue-from-philosophers-stone. Acesso em: 12 Maio 2020.

16. WIZARDING WORD DIGITAL. Things you may not have noticed about... albus Dumbledore. 2018. Disponível em: https://www.wizardingworld.com/ features/things-you-may-not-have-noticed-about-albus-dumbledore. 